\title{
TRENDS IN TECHNICAL AND TACTICAL MODIFICATIONS AMONG COMPETITORS OF VARIOUS NATIONALITIES BASED ON RESEARCH CONDUCTED DURING THE 2009 WORLD YOUTH CHAMPIONSHIP IN GRECO-ROMAN STYLE WRESTLING IN TURKEY
}

\author{
Technical and tactical operations in classical style wrestling \\ (Greco-Roman) among different nationalities
}

\author{
ARTUR KRUSZEWSKI ${ }^{1}$, STANISŁAW KUŹMICKI ${ }^{1}$, MAREK KRUSZEWSKI ${ }^{1}$, \\ WŁADYSEAW JAGIEŁŁO \\ ${ }^{1}$ Jozef Pilsudski University of Physical Education in Warsaw \\ ${ }^{2}$ Gdansk University of Physical Education and Sport
}

Mailing address: Artur Kruszewski, Jozef Pilsudski University of Physical Education in Warsaw,
ul. Marymoncka 34 01-813 Warszawa, e-mail: artur.kruszewski@awf.edu.pl

\begin{abstract}
Introduction. This paper discusses the relationship between the technique implemented during competition and the end result including an attempt to evaluate the technical and tactical preparation of different nationality competitors in GrecoRoman wrestling. The research was conducted during the 2009 Junior World Cup in Turkey. Material and methods. The research material included a video recording posted by the International Federation of Associated Wrestling Styles (FILA) on their website. The material contained recordings of 240 matches. An analysis of 212 matches with competitors from 49 countries was conducted; each team selected one competitor in each weight category (up to 8 competitors in total). Results and conclusions. During the competition there was strong correlation between victory and the execution of the roll-through and the combat zone and result defence, also in the ground position. Competitors from Russia and Iran, who were most successful, winning 6 and 4 medals respectively, obtained an average of 3.18 technical points in each match. Among the sample analysed this was the lowest score, indicating the optimal use of technical and tactical skills by the competitors resulting in a victory.
\end{abstract}

Keywords: martial arts, Greco-Roman wrestling, combat analysis

\section{Introduction}

As the standard of athletes participating in major wrestling events increases, the authors wished to address the issue of the dominance of certain nationalities in wrestling. In a wider view this led to the following question: Does attendance at certain training schools result a competitive advantage in wrestling? Analysis of sportsmanship is not a common topic of scientific research. The authors focussed mainly on adaptive changes in the competitors $[1,2,3,4,5]$. The authors proposals on how to analyse the conduct of the combat and how to assign significance to the particular elements of combat vary slightly. Nevertheless, all authors agree on the necessity of this type of research. The issue of objective observation of the competitors is becoming increasingly popular in all sports, both measurable and unmeasurable. The authors emphasise the usefulness of competitor observation as the key element in the process of the competitor results evaluation $[6,7,8]$.

\section{Material and methods}

The research material included a video recording posted by the International Federation of Associated Wrestling Styles
(FILA) on their website. The material contained the recording of 240 matches.

Additionally, the authors used judge protocols for each judged weight category, prepared during the competition. Seven most effective representations were identified in this group. Among the selected representations, Polish representation was chosen as the comparison representation for the analysed combat parameters.

212 competitors from 49 countries participated in the competition and each team selected one competitor in each weight category (up to 8 players in total).

During the observation part of the research material the course of the match was carefully recorded on specially designed registration sheets. The data obtained was then put into Excel spreadsheets. The sheets covered a number of categories created to address various research purposes. The sheets included data on weight category, duration of the match, technical activities performed in the "standing" and "ground" positions, scores obtained for particular technical activities and the efficiency of the competitors from various nationalities.

To evaluate the relation between the number of match and specific parameters, statistical analysis was carried out in which the correlation coefficient was used.

The indicators of activity, passivity and efficiency were also 
Table 1. The analysis of the combat structure of selected national teams during the 2009 World Junior Championships

\begin{tabular}{|c|c|c|c|c|c|c|c|c|}
\hline \multirow{2}{*}{ Parameter } & \multicolumn{7}{|c|}{ Nationality } & \\
\hline & RUS & IRI & AZE & KGZ & ARM & TUR & POL & \\
\hline Number of medals & 6 & 4 & 3 & $\cdot$ & $\cdot$ & $\cdot$ & $\cdot$ & \multirow{2}{*}{ Correlation } \\
\hline Bouts & 38 & 32 & 25 & 18 & 21 & 23 & 18 & \\
\hline Technical points / match & $121 / 3.18$ & $102 / 3.18$ & $106 / 4.24$ & $81 / 4.5$ & $82 / 3.90$ & $98 / 4.26$ & $36 / 2$ & 0.767 \\
\hline$\%$ Takedowns of all actions & $19 / 23.4 \%$ & $10 / 14.9 \%$ & $8 / 12.5 \%$ & $9 / 18 \%$ & $13 / 25 \%$ & $14 / 22.2 \%$ & $8,29.6 \%$ & 0.651 \\
\hline$\%$ Throws of all actions & $5 / 6.1 \%$ & $4 / 5.9 \%$ & $10 / 15.6 \%$ & $7 / 14 \%$ & $2 / 3.8 \%$ & $3 / 4.7 \%$ & $0 / 0 \%$ & 0.201 \\
\hline$\%$ Trolley of all actions & $30 / 37 \%$ & $26 / 38.8 \%$ & $29 / 45.3 \%$ & $24 / 48 \%$ & $24 / 46.1 \%$ & $26 / 41.2 \%$ & $9 / 33.3 \%$ & 0.614 \\
\hline$\%$ The combat zone and result defence of all actions & $25 / 30.8 \%$ & $26 / 38.8 \%$ & $17 / 26.5 \%$ & $10 / 20 \%$ & $13 / 25 \%$ & $19 / 30.1 \%$ & $10 / 37 \%$ & 0.932 \\
\hline Performed actions & 81 & 67 & 64 & 50 & 52 & 63 & 27 & 0.850 \\
\hline
\end{tabular}

calculated on the basis of the following formula [9]:

1. Activity Index

$\mathbf{A} \mathbf{I}=$ technical points +10 points for the touch / number of match

2. Passivity Index

$\mathbf{P I}=$ warnings and passivity / number of match

3. Efficiency Index

$\mathbf{E I}=$ match ended by touch $/$ number of match

\section{Results}

Russian competitors took part in the highest number of matches (38), scoring a total of 121 technical points (an average of 3.18 points per match). The Russians were also the most successful in takedown and roll-through actions. Competitors from Azerbaijan were the most active team in the "standing" position, performing 18 actions of this type in a total of 25 matches in which they participated. This team in general were very active, performing numerous and varied technical actions during the tournament. One of the team's victories was achieved by touch and only one warning for passivity was issued.

Iran produced the most effective defensive team measures, including in the combat zone and result defence. Their competitors participated in a total of 32 matches and performed 67 technical actions, $38 \%$ of which belonged to the defensive action group (Tab. 1).

The research indicates the growing dominance of ground work with respect to all nationalities, including in the combat zone and result defence $\mathrm{r}=0.932$. However, the number of actions performed in the standing position and the conduct of defensive operations is distributed in similar proportions in all subgroups. Interestingly, the Iranian team yielded the same value for technical activities performed in the roll-through and "the combat zone and result defence" (38\%).

Similar results were obtained by the Polish national team, for whom the most efficient combat element turned out to be the combat zone and result defence performed during ground work. $37 \%$ of all technical actions performed, for which Polish competitors won points, were granted for defence actions. Therefore this turned out to be the most effective way to earn points by Poland.

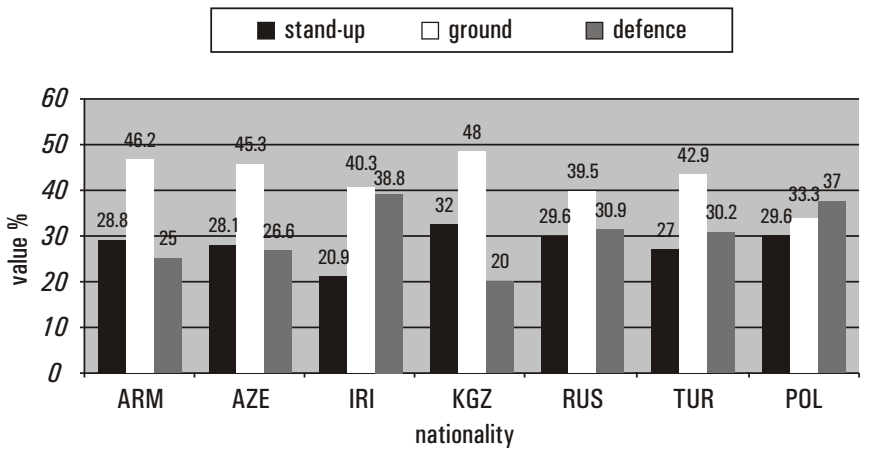

Figure 1. The characteristics of the techniques performed in the "stand-up" and "ground" positions and defensive actions during the 2009 World Junior Championships

The highest Activity Index (AI) was obtained by Azerbaijan (4.6), and Kyrgyzstan (4.5); the Polish and Russian national teams obtained the lowest indexes (2.6 and 3.2 respectively). The Russians performed the highest number of technical activities and participated in the highest number of matches.

The relatively low index obtained by Russians (IA) was caused by their choice of techniques, preferring low-scored techniques. This is confirmed by the analysis of the data gathered in the observation sheet; out of 66 technical activities performed 33 scored one point only.

Turkey was assessed as the most passive group of competitors in the competition with a PI $=0.13$. Passive techniques include the actions of combat avoidance and fouls. Poland and Kyrgyzstan did not receive any warnings for the use of passive techniques.

The highest Efficiency Index for the roll-through was obtained by Kyrgyzstan (1.3); in 18 matches the team performed 24 takedown actions on the ground. The lowest (0.5) EIt was obtained by the Polish team. The Poles, during the 18 matches they participated in, performed only nine roll-through actions.

The next indicator analysed was the Efficiency Index of defensive actions (EId). This category includes "defence of the combat zone" actions as well as "defence of the result" performed in the last thirty seconds of each round. The highest score was obtained by Iran (0.81); during the 32 matches they participated in, they obtained their points thanks to the implementation of the combat zone and result defence techniques performed in the forced ground as many as 26 times.

The lowest EId (0.56) was obtained by Poland and Kyrgyzstan. Both teams participated in eighteen matches and received technical points for defence only nine times.

Teams with highest activity index (AI) obtained the same 
amount of technical points for the roll-through (EIt). The rollthrough takedown action is the most effective technique used in the classical (Greco-Roman) style of wrestling.

Table 2. The combat indexes obtained by the selected national teams

\begin{tabular}{|l|c|c|c|c|c|c|c|}
\hline \multirow{2}{*}{ Parameter } & \multicolumn{7}{|c|}{ Nationality } \\
\cline { 2 - 8 } & RUS & IRI & AZE & KGZ & ARM & TUR & POL \\
\hline $\begin{array}{l}\text { Activity Index } \\
\text { (Al) }\end{array}$ & 3.2 & 3.5 & 4.6 & 4.5 & 3.9 & 4.3 & 2.6 \\
\hline $\begin{array}{l}\text { Passivity Index } \\
\text { (PI) }\end{array}$ & 0.05 & 0.06 & 0.04 & 0 & 0.05 & 0.13 & 0 \\
\hline $\begin{array}{l}\text { Efficiency Index } \\
\text { for trolley (Elt) }\end{array}$ & 0.8 & 0.8 & 1.2 & 1.3 & 1.1 & 1.1 & 0.5 \\
\hline $\begin{array}{l}\text { Efficiency Index } \\
\text { for the combat zone } \\
\text { and result defence (Eld) }\end{array}$ & 0.66 & 0.81 & 0.68 & 0.56 & 0.62 & 0.83 & 0.56 \\
\hline
\end{tabular}

Technique efficiency is reflected in the number of medals received by each team during the Junior World Championships. Russia won six medals in total, which makes them the most successful team in the competition. Iran was in second place with four medals in total, followed by Azerbaijan with three medals in total. The biggest surprise was the distant $24^{\text {th }}$ position of the Ukraine, once the world's strongest team in GrecoRoman wrestling in this age group, who received only one scoring position.

\section{Discussion}

The World Championship is one of the most significant sporting events for its competitors. The participation of top class sportsmen indicates that the match analysis during the competition reflects the main trends in technical and tactical modifications of competitors of various nationalities.

When conducting an analysis it should be emphasised that Russia and Iran, who gained the highest number of medals, did not perform the highest number of technical activities (on average $3.18 /$ match); in fact they obtained the lowest scores in this category. At the same time they proved to be the most successful in the combat zone and result defence $(38.8 \%$ and $30.8 \%$ for Iran and Russia respectively). It can then be assumed that these two elements were then most significant in obtaining the overall success of the teams of Russia and Iran. This interpretation is also confirmed by statistical analysis which indicates a high correlation between the points obtained through the combat zone and result defence and the total number of matches $(\mathrm{r}=0.932)$.

Further analysis of preferred positions indicates that the most commonly used is the ground position. Kruszewski et al [10] points out the popularity of the ground position (75\% of all technical points) among female competitors participating in the Olympics; in this case the results do not vary within different weigh categories. The results of Sterkowicz and Franchini, who conducted a thorough analysis of judo competitors, were slightly different [11]. Analysing judo combat from 1995-1999 they reached the conclusion that the competitors in the lightweight category chose to perform technical activities (64.76\%) significantly more often than the competitors in the heavyweight categories.

The combat structure indicators suggest a high diversity of technical and tactical strategies among various nations. Analysis of the match performed by the two leading teams (Russia and Iran) confirms previous observations. The low level of Activity Index (3.2 and 3.5 for Russia and Iran respectively) indicates the fact that the competitors of these nations decided to avoid the risk of implementing technical actions but, when such actions were performed, they proved to be highly effective (Efficiency Index for the competitors of Iran and Russia amounted to 0.81 and 0.66 respectively).

\section{Conclusions}

1. During the competition the determining element of victory was the performance of the so-called roll-over in the ground position (37\% of Russia and $46.1 \%$ of Armenian competitors) and the defence of the result, also in the ground position (20\% of Kazakhstanis and $38.8 \%$ of Iranians).

2. Russia and Iran, the teams with the highest number of medals ( 6 and 4 respectively) obtained an average of 3.18 technical points in each match. It was the lowest score among the teams analysed, indicating an optimal use of technical and tactical skills, which resulted in match victory.

3. As the standard of athletes participating in major wrestling events becomes more equal, it has been proven that the ultimate success in wrestling competitions at the highest level not only depends on the ability to perform technical activities but is equally dependant on the ability to defend the result in the ground position; this skill correlates highly with the number of matches won, $\mathrm{r}=0.932$.

\section{Literature}

1. Błach, W. (2005). Selected aspects of training and sport combat. Warszawa: COS. [in Polish]

2. Cvetković, C., Marić J. \& Marelić N. (2005). Technical efficiency of wrestlers in relation to some anthropometric and motor variables. Kinesiology vol. 37, no. 1, 74-83.

3. Ranione, J. \& Hughest B. (2004). Body-weigh fluctuation in collegiate wrestlers: implication of the national collegiate athletic association weight-certification program. Journal of athletic training, 39(2); 162-168.

4. Rezasoltani, A. et al. (2005). Cervical muscle strength measurement in two groups of elite Greco-Roman and free style wrestlers and a group non-athletic subjects. British Journal of Sports Medicine, 39(7), 440-443.

5. Trzaskoma-Bicserdy, G., Bognar J. \& Ozsvath K. (2007). Predictive value of somatic features and of results of motor test in junior wrestlers. Physical Education and Sport, 51, 23-27.

6. Kruszewski, A. \& Brańka S. (2006). Analysis of the structure of a wrestling bout at the junior European Championship Wroclaw 2005. Movement and health, International Conference 17-18 November 2006, Glucholazy, Z. Borysiuk (Ed.), pp. 394-400.

7. Kruszewski, A., Jagiełło W. \& Adamiec A. (2008). Technical fitness of judoists (Wright category - $66 \mathrm{~kg}$ ) participating in European Championships 2005. Physical Education and Sport, 52 (2), 95-97.

8. Sterkowicz, S. \& Franchini E. (2000). Techniques used by judoists during the world and Olympic tournaments 19951999. Human movements 2(2), 24-33.

9. Adam, M. (1984). Registration and technical and tactical evaluation of judoists preparation. Zeszyt metodyczny AWF Gdańsk 1 (15-27). [in Polish] 
10. Kruszewski, A., Jagiełło W. \& Kucharska E. (2009). Characteristics of technical and tactical actions of female wrestlers in the Olympic Games in Beijing 2008. Sport Wyczynowy nr 3, 35-41. [in Polish]

11. Sterkowicz, S. \& Kozioł J. (1994). Analysis method of fights tactics in judo. Annuals of Cracow Academy of Physical Education, pp. 113-133.

\section{Appendix}

Definitions of terms used in the paper:

"Pin" - the main purpose of wrestling, other names include "shoulder position", or "back position". In this position the competitor holds their opponent in such way, that the opponent touches the mat with the back from the shoulders to the lower part of the shoulder blades for a minimum of 1 second. This position ends the match before the regular match time.

"Stand-up" - the combat position in which both competitors, standing on the mat (combat zone), are able to perform technical activities.

"Ground" - the combat position in which one of the competitors is kneeling or lying down facing the mat position, with his opponent behind.

"Takedown" - a group of technical activities used in the standing position, which aim at bringing an opponent to the ground position. In accordance with the applicable rules the judges grant 1 technical point for the successful performance of such activity.
"Throw" - a group of technical activities used in the standing position, which aim to bring the opponent to the danger position. In accordance with the rules the judges grant 3 or 5 technical points for the successful performance of such activity.

"Roll-over" - technical activity used during combat in ground position consisting of rolling on the side gripping the opponent resulting in turning his back to touch the mat.

"Combat zone and result defence" - if match victory cannot be granted, one of the competitors assumes the ground position and attempts to prevent the opponent from performing a technical action. Should the attempt be successful the competitor is granted 1 technical point and wins the round; should the attacking competitor manage to perform the technical action they receive the technical points and win the round.

Submitted: February 28, 2011

Accepted: June 13, 2012 